\title{
A New Machine Learning Framework for Effective Evaluation of English Education
}

\author{
https://doi.org/10.3991/ijet.v16i12.23323 \\ Lei Zhang \\ Jilin Institute of Chemical Technology, Jilin, China \\ goldenchina_79@163.com
}

\begin{abstract}
With the rapid development of information technology, English education has attracted the interest of scholars for its ability to rely on computers to analyze and understand human language. Taking machine learning (ML) as the core, this paper tries to develop an evaluation system for ML-based English education. Specifically, a basic ML model was established with four stages: environment, knowledge base, learning process, and implementation process. The entire ML system was divided from top to bottom into a user layer, a business layer, and a data layer. Application results show that, during the ML, even users with similar personal data and the same goal have vastly different suitable learning materials, due to their gap in personal capabilities. The research provides an effective way to evaluate English education in the context of computer science and artificial intelligence.
\end{abstract}

Keywords - Information technology, English education, machine learning (ML), evaluation system, artificial intelligence

\section{$1 \quad$ Introduction}

In China, English is a subject that has realized information management in earlier years; later, English education has gradually transformed from the traditional audiovideo teaching method to the modern multimedia, networked, and interactive teaching method [1]. In terms of educational informatization, English education is always at the front edge in aspects of teacher experience inheritance, learning atmosphere informatization, and construction investment [2,3]. With the progress of computer science and artificial intelligence, machine learning languages have become the focus of current research, including speech recognition, speech synthesis, and natural language processing, etc. [4, 5].

With the rapid development of ML technologies with deep artificial neural networks as the kernel, now ML has been widely used in the field of natural language processing [6, 7]. The fast development of ML technologies and ready-to-use hardware equipment have inspired researches on the application of ML in communication networks [8]. To enable machines to handle complex natural language processing tasks, at first, we must grant the machines the ability to understand natural language $[9,10]$. In the field of traditional computational linguistics, scholars describe words in 
natural language as an extremely sparse high-dimensional vector [11]. In terms of English education, firstly, the English vocabularies are embedded in a machine, then, by incorporating diverse existing vocabulary-embedded vector sets and semantic knowledge libraries, a kind of higher-quality vector sets are generated to represent the vocabularies [12]. For the retrieval technology based on grammatical information and the personalized recommendation technology in online learning, English vocabulary embedding can be used as an assistive technology to further improve the learning effect $[13,14]$.

Effective evaluation of education is an interdisciplinary research field that conducts analysis from the perspectives of pedagogy and sociology, and now a new perspective of institutional economics has been added to the education evaluation $[15,16]$. In English education, the implementation of an effective evaluation mechanism is conducive to the enrichment and development of educational management and pedagogical theory [17]. Under the ML framework, the effective evaluation of English education is conducive to perfecting the evaluation system of higher education and improving the quality of higher education [18, 19]. With ML as the kernel, this paper attempts to develop an evaluation system for ML-based English education, in the hopes of providing an evaluation method for English education in the context of computer science and artificial intelligence.

\section{The ML-Based English Learning Research}

\subsection{ML theory}

As computer technology is developing at a fast speed, people are exposed to more and more information, however, it's getting increasingly difficult for people to quickly obtain the most useful and accurate information from the sea of information [20]. ML is one of the most valued information technologies that has been widely applied in the fields of data mining, natural language processing, speech and handwriting recognition, strategy-type games, and robot applications [21, 22]. ML is a process of using various methods to allow computers to imitate the learning process of the human brain to obtain new knowledge, and optimizing the performance of the computer using the acquired knowledge [23, 24]. It is a method for computers to realize selfperfection through learning new knowledge, acquiring new methods, identifying mastered content, gradually improving performance, and constantly giving feedback [25]. The prediction or reasoning methods adopted in ML are called the learning strategies, which include three types: search type, construction type, and planning type [26, 27]. Figure 1 gives the basic model of ML, which includes four stages. The environment represents the source of knowledge information; the knowledge base represents the knowledge mastered by the system; the learning link represents the process of the system learning knowledge from the outside world to enrich its own knowledge base; the implementation process represents the system's ability to complete tasks, in this stage, the system completes certain tasks according to the acquired knowledge in the knowledge base and gives feedback to the learning process. 
Figure 2 shows the number of people who are active in ML-assisted English learning. According to the figure, the number of active users of the app BaiCiZhan is the most, this app creatively combines graph memory with word memory and takes a game form to increase the interest of learning. Figure 3 is a function flowchart of the ML-assisted English vocabulary learning, the system guides users to conduct English vocabulary learning by setting learning plans and pushing vocabulary lists according to the Ebbinghaus forgetting curve.

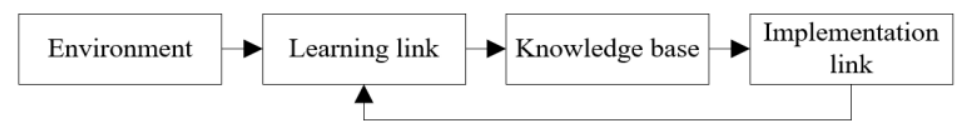

Fig. 1. Basic model of ML

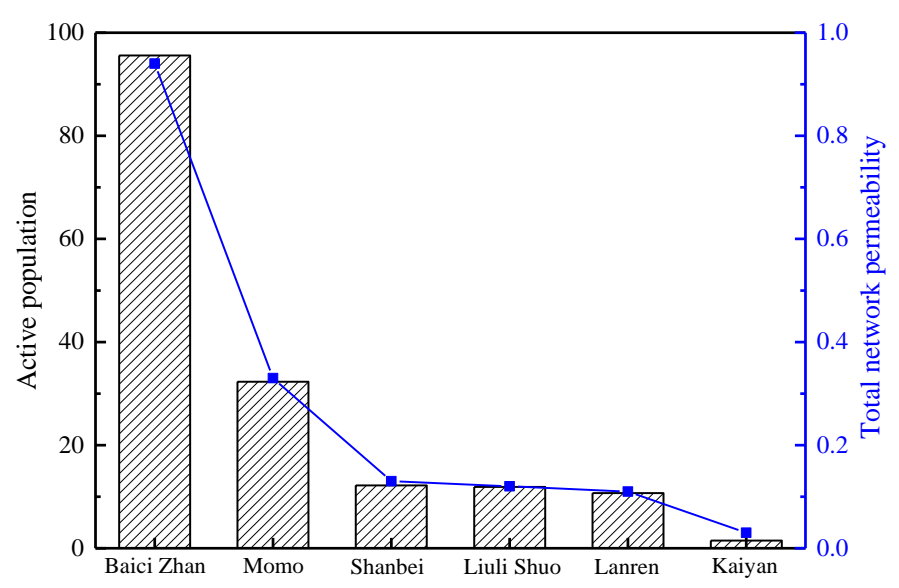

Fig. 2. Statistics of active users of a few ML-assisted English learning apps

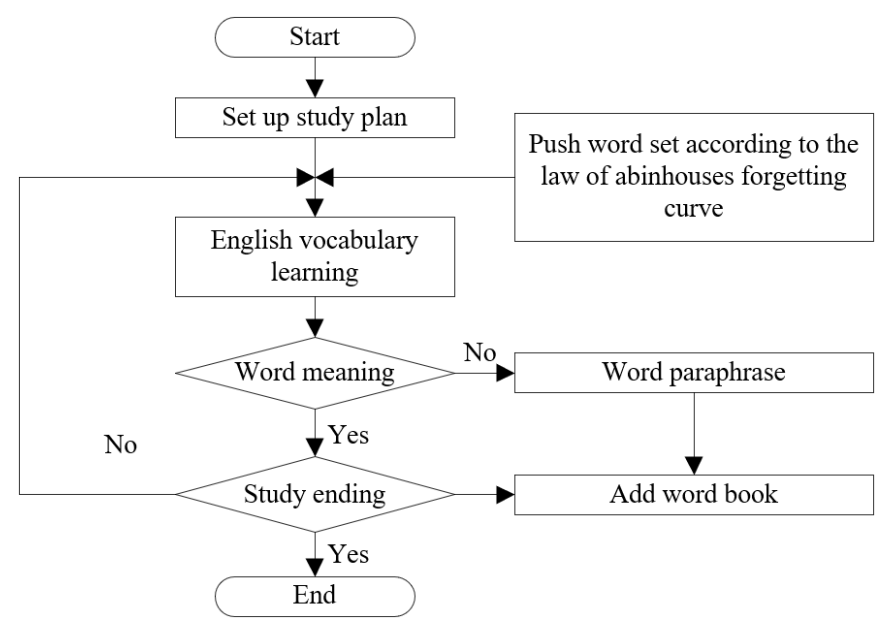

Fig. 3. Function flow of ML-assisted English vocabulary learning 


\subsection{Theoretical model of transformational learning}

Transformational learning is a special learning method, it is a qualitative-changing learning method that has the features of inclusive, open, and emotionally reactive, so it can generate more correct and reasonable ideas and opinions [28]. The process of transformational learning is the internal psychological and behavioral procedures experienced by learners during their transformational learning [29]. The result of transformational learning is the profound and continuous changes that have taken place $[30,31]$. The educational practice of transformational learning is the projects, experience, intervention measures and teaching practice designed to achieve the goals of transformational learning [32].

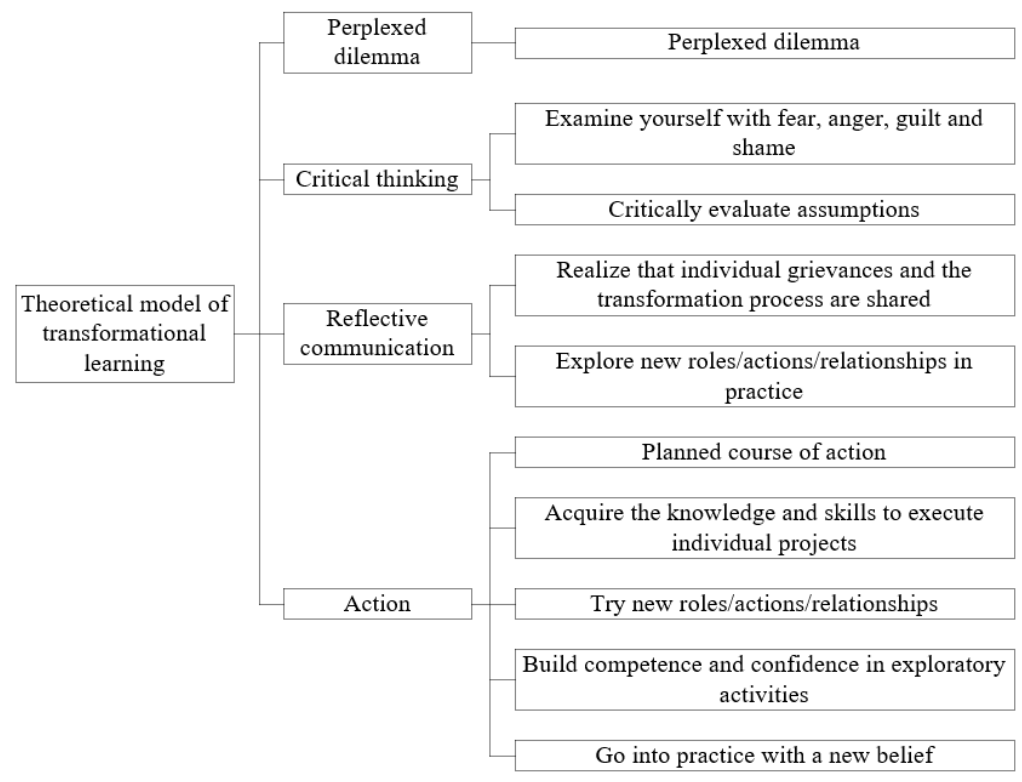

Fig. 4. Theoretical model of transformational learning

Figure 4 shows the theoretical model of transformational learning, which is divided into four stages: perplexed dilemma, critical thinking, reflective communication, and action. In the critical thinking stage, learners need to examine themselves with fear, anger, guilt, and shame, and critically evaluate the assumptions. In the reflective communication stage, learners should realize that individual grievances and transformation process are shared, and they need to explore new roles/actions/relationships in practice. In the action stage, learners should plan their action routes, acquire the knowledge and skills to execute individual projects, build competence and confidence in exploratory activities, and engage in practice with new ideas. Figure 5 shows the transformational learning processes, including triggering event, teacher reflection, dialogue, action, and results. After going through these stages, positive results will happen to the cognitive transformation of learners. Figure 6 shows the influencing factors of transformational learning. Transformational learning needs to undergo 
transformations in many aspects, such as teaching ideas, scientific research ideas, interpersonal relationship ideas, career development ideas, and outlook on life, etc.

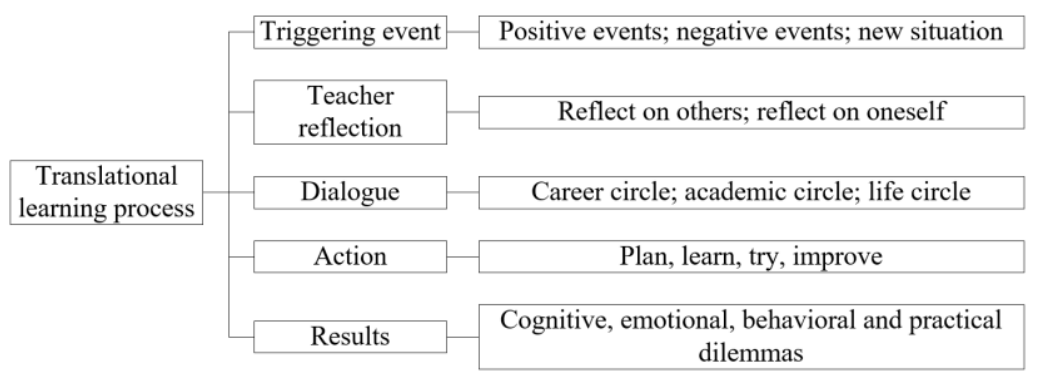

Fig. 5. Transformational learning processes

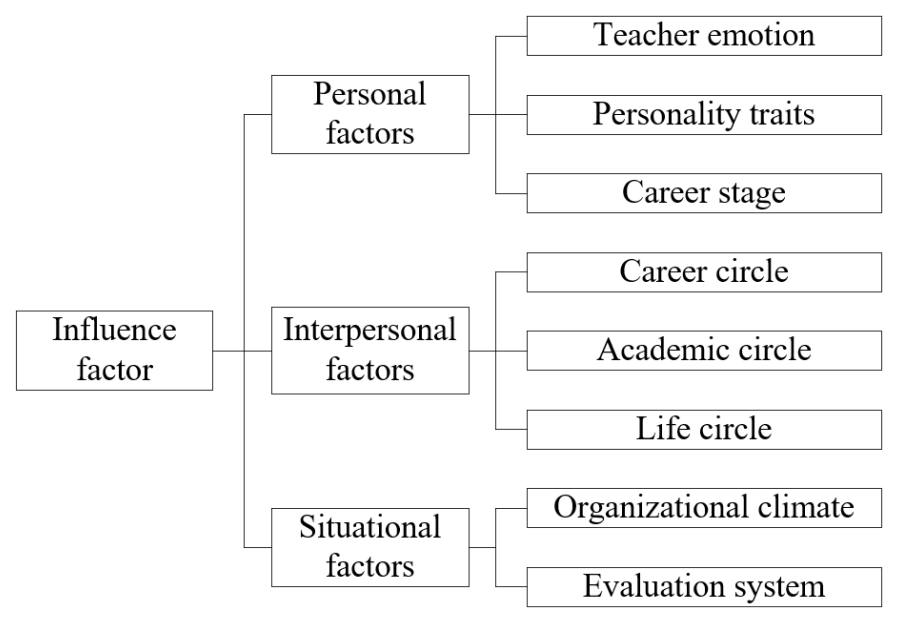

Fig. 6. Influencing factors of transformational learning

\section{$3 \quad$ English Education Methods Based on Deep Learning}

\subsection{ML-assisted personalized learning system}

The popularization of Internet technology has provided a convenient and effective environment for the ML-assisted personalized learning system. As online learning resources are increasing constantly, learners have more and more choices. During ML, users with similar personal data and the same goal may have vastly different suitable learning materials due to their gap in personal capabilities. Figure 7 shows the competence model for English learners. The model has three aspects of learning result, emotional attitude, and learning transfer; wherein the learning result includes the objective and subjective result data of the completed tests, as well as the accuracy of vocabulary review and word discrimination; the emotional attitude includes initiative 
(subdivided into learning motivation and autonomous learning) and engagement (subdivided into learning perseverance and interactive); the learning transfer includes learning strategy and innovation ability. According to the different data type, the learner data of the ML-assisted personalized learning system can be divided into the numerical type, the text type, and the mixed type. Figure 8 gives the intelligent recommendation model for personalized learning. According to learner data (text data, operation data, and basic information) and learning ability characteristics, learning style characteristics, resource form characteristics, and resource content characteristics described by the resource data, the system generate English vocabulary lists and push them to learners following certain recommendation strategies.

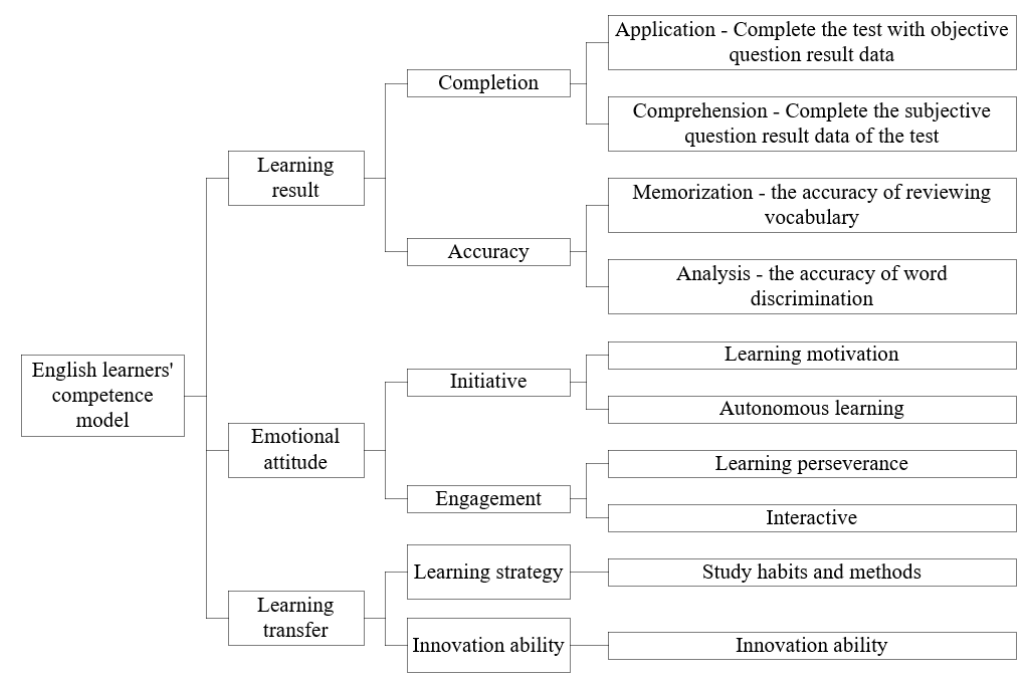

Fig. 7. The competence model for English learners

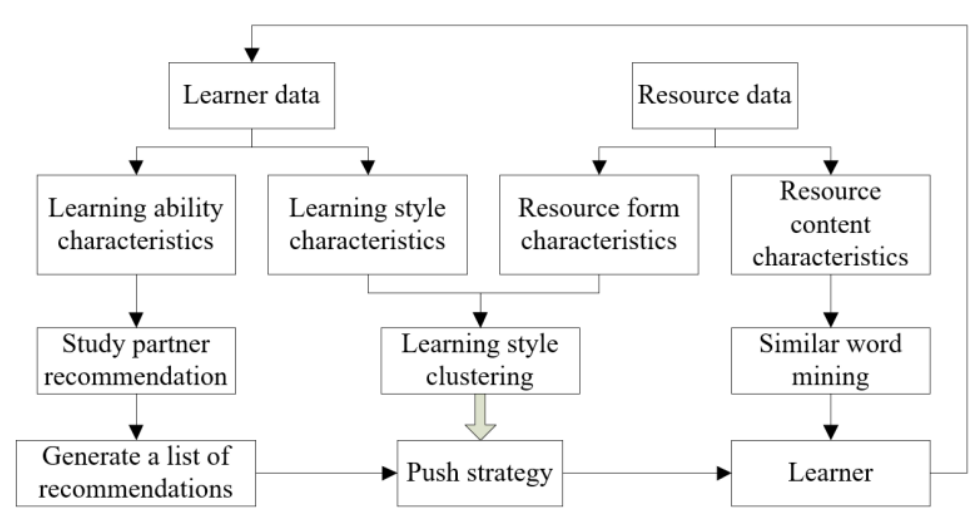

Fig. 8. Intelligent recommendation model for personalized learning 


\subsection{End-to-end ML method based on deep learning}

The research on communication system studies channel modeling and designs optimal data transmission method. The classic communication systems are generally divided into multiple artificially defined independent modules, each module is optimized separately to solve the problem of signal transmission in channels. Although optimizing each module can indeed improve the overall performance of the system, the optimal solution combination of individual modules may not generate the overall optimal solution. Since the coding of the transmitting end of the end-to-end communication system constantly and iteratively trains and updates the parameters to achieve the optimal demodulation effect, it had been adopted in this study. Figure 9 gives a framework diagram of the ML system. The entire system consists of three modules, from top to bottom, they are the user layer, the business layer, and the data layer. The data layer provides data storage service and assumes the responsibility of ensuring data reliability and security; this layer stores user information database, user behavior database, test database, lexical database, and corpus database, etc. The business layer implements the core business logics of the recommendation system, including mining similar vocabularies, mining similar users, using user-based collaborative filtering algorithm to recommend vocabulary lists to learners, using clustering algorithm to determine user learning style, and adjusting pushing methods, etc. The user layer is responsible for the direct interaction between learners and the system, the server's responds to user requests, and the result content display, including functions such as vocabulary learning, information registration, likes and comments, corpus upload, and completion of tests, etc.

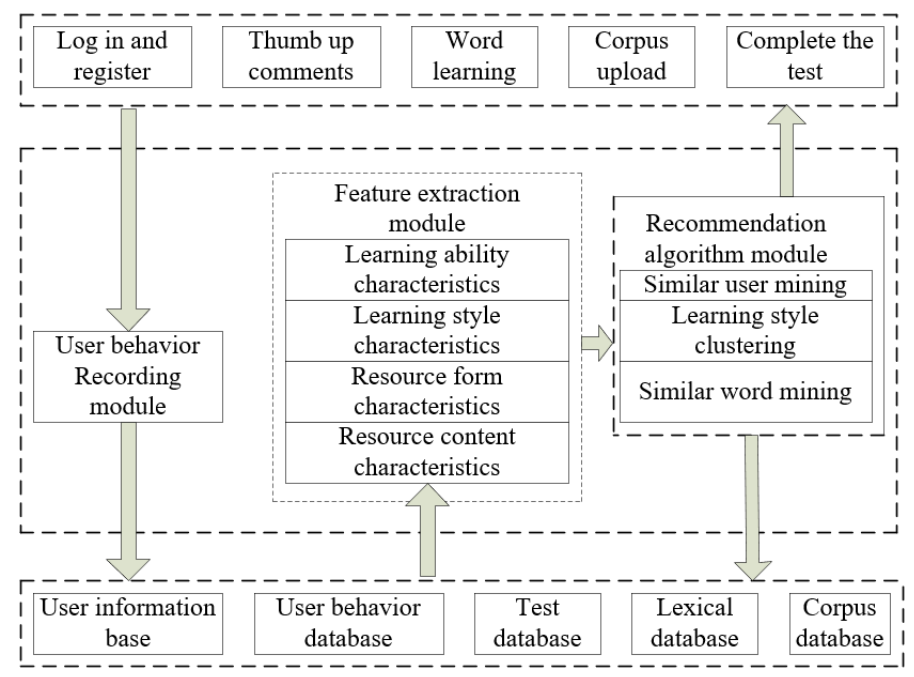

Fig. 9. Framework diagram of the ML system 


\section{The Current Situation of English Education Evaluation Informatization and Problems in It}

\subsection{Problems with English education evaluation informatization}

In terms of educational informatization, English education is always at the front edge in aspects of teacher experience inheritance, learning atmosphere informatization, and construction investment. The informatization level of English education evaluation can reflect the current situation of the management informatization of English education to a large extent. Figure 10 lists the problems with the informatization of English education evaluation:

First, viewing from the perspective of education department, the planning of education management informatization is flawed, it lacks evaluation and incentive mechanism to encourage teachers to conduct information-assisted teaching, resulting that the management informatization of English education hasn't been fully developed. In addition, the insufficient investment in English education management informatization has resulted in hardware equipment aging damage, which has seriously affected the informatization level of English education management in various units.

Second, viewing from the perspective of schools, the planning of English teaching management informatization is incomplete, schools generally have not formulated specific work policies that conform to the actual situations of the schools; the management informatization organization of English teaching is incomplete, the construction work of management informatization still stays at the theoretical stage, and it is impossible to operate efficiently and systematically; in addition, high-quality digital education resources is insufficient, this is mainly due to the lack of an overall plan for the construction of such high-quality digital education sources, and it has resulted in situations such as the low-level and repetitive construction of education resources, the waste in education funds, and the low-quality digital education resources, etc.; moreover, there's a shortage in professional technicians and instructors for education informatization, which has hindered the development of education informatization level of schools; at last, insufficient efforts have been made to promote English education informatization to the management of faculty, which is mainly because the existing English education in schools has not truly applied information technology to teaching and information management.

Third, viewing from the perspective of teachers, there are differences in their understanding of the management informatization of English education, which is mainly reflected as the phenomenon that young teachers generally have stronger ability to accept new things and new knowledge and they can easily understand the management informatization of English education, while senior teachers with rich educational experience are not clear about the process of the independent innovation of education informatization, as a result, there're differences in teachers' enthusiasm for the management informatization of English education. In addition, there're also differences in teachers' mastery level of the management informatization of English education, the education department hasn't paid enough attention to the cultivation of teachers' abil- 
ity in information management of English education. Moreover, the integration of information technology and English courses is not deep enough.

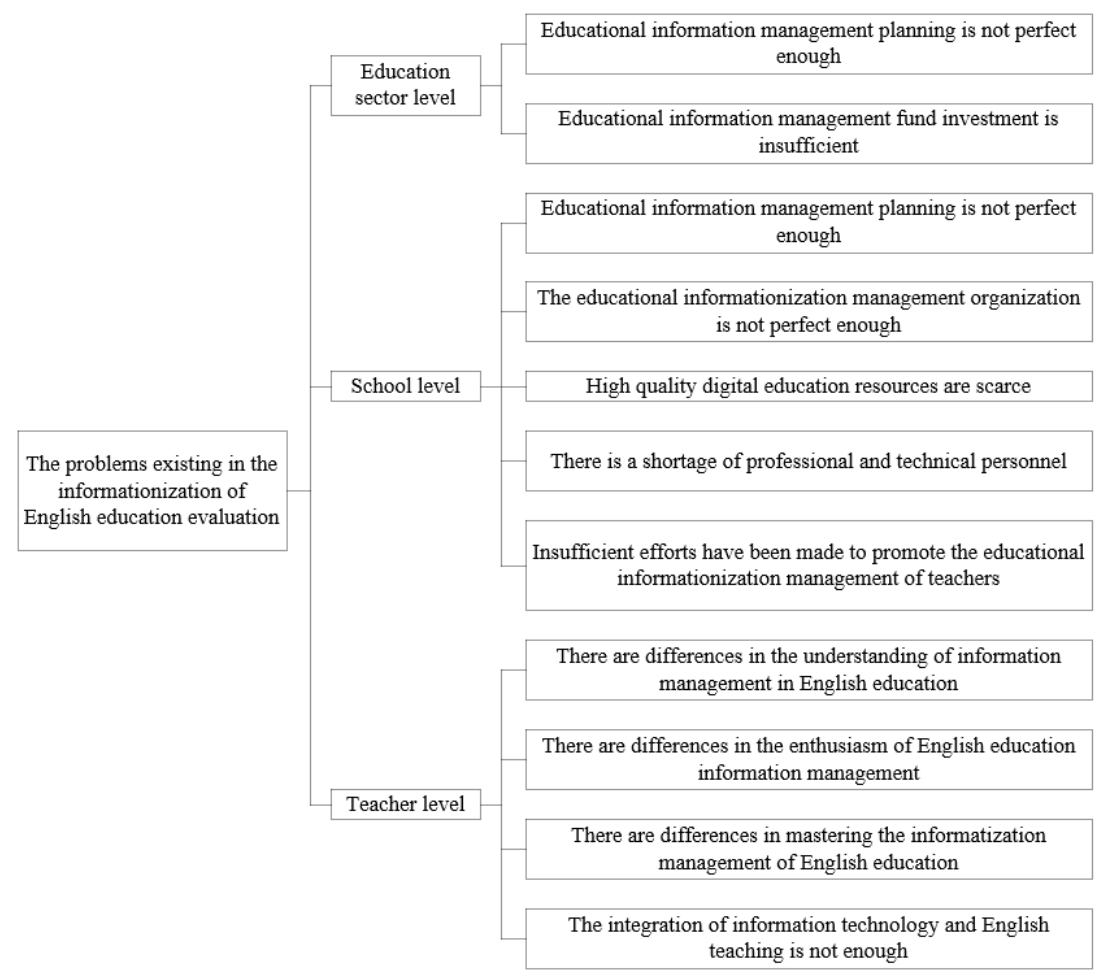

Fig. 10.Problems with the informatization of English education evaluation

\subsection{Countermeasures for the informatization of English education evaluation}

Figure 11 proposes a few countermeasures for the informatization of English education evaluation. Aiming at the problems with the informatization of English education evaluation and their causes analyzed above, this paper proposes the corresponding countermeasures also from the three perspectives of the education department, the schools, and the teachers.

First, from the perspective of education department, administrators at education department should formulate scientific development plans for the management informatization works of English education, raise people's awareness of the importance of such development plans, formulate the plans from top down in hierarchies and in steps, ensure relative flexibility in the development plans, and pay attention to the effective execution of such development plans. Moreover, education department should also increase the investment in management informatization of English education, expand the sources of funds, and establish a long-term mechanism for raising funds for the management informatization of English education. 
Second, from the perspective of schools, the schools need to improve the plans for the management informatization of English education, standardize the management organization of English education informatization, establish a mechanism for sharing and co-construction of high-quality digital English education resources, increase job positions of professional technicians, and strengthen faculty construction for the management informatization of English education.

Third, from the perspective of teachers, they need to deepen their understanding of the importance of the management informatization of English education, take the initiative in learning the new information technology required for the management informatization of English education, enhance their ability to master the information technology required for the management informatization of English education, and actively promote the integration of information technology and the English courses.

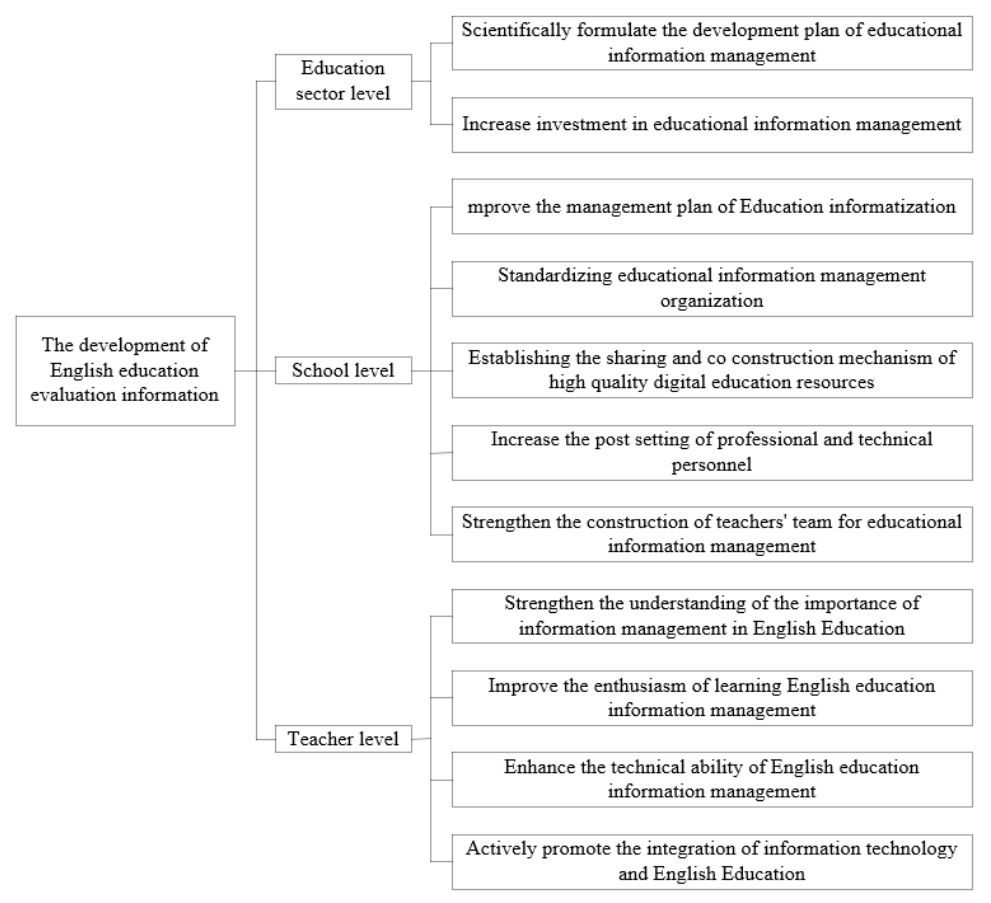

Fig. 11. Countermeasures for the informatization of English education evaluation.

\section{Conclusion}

This paper developed an evaluation system for ML-based English education. The specific conclusions are: 
1. The basic model of ML includes four stages: environment, knowledge base, learning process, and implementation process. The environment represents the source of knowledge information; the knowledge base represents the knowledge mastered by the system; the learning link represents the process of the system learning knowledge from the outside world; and the implementation process represents the system's ability to complete tasks.

2. During the ML, even users with similar personal data and the same goal have vastly different suitable learning materials, due to their gap in personal capabilities.

3. The entire system consists of three modules, which are the user layer, the business layer, and the data layer from top to bottom. The data layer provides data storage service; the business layer implements the core business logics of the recommendation system; and the user layer is responsible for the direct interaction between learners and the system, the server's responds to user requests, and the result content display.

4. The informatization level of English education evaluation can reflect the current situation of the management informatization of English education to a large extent. This paper analyzed the current situations and the causes of problems of the informatization of English education evaluation from the three perspectives of education department, schools, the teachers and proposed a few corresponding countermeasures.

\section{Acknowledgement}

This article is a periodical achievement of the 13th "Five-Year Plan" schemed project (2020) of Jilin Educational Science Institute-The Guarantee Mechanism of Cultivating English Majors' Critical Thinking under the Background of New Liberal Arts (Grant No. GH20288).

\section{$7 \quad$ References}

[1] Liu, H., Chen, R., Cao, S., Lv, H. (2020). Evaluation of College English Teaching Quality Based on Grey Clustering Analysis, International Journal of Emerging Technologies in Learning, 16(2): 173-187. https://doi.org/10.3991/ijet.v16i02.19727

[2] Dickinson, K.J., Bass, B.L., Pei, K.Y. (2020). The current evidence for defining and assessing effectiveness of surgical educators: a systematic review. World Journal of Surgery, 44(10): 3214-3223. https://doi.org/10.1007/s00268-020-05617-9

[3] Zhang, G. (2020). A study of Grammar Analysis in English Teaching with Deep Learning Algorithm, International Journal of Emerging Technologies in Learning, 15(18): 20-30. https://doi.org/10.3991/ijet.v15i18.15425

[4] Guill, K., Lüdtke, O., Köller, O. (2020). Assessing the instructional quality of private tutoring and its effects on student outcomes: Analyses from the German National Educational Panel Study. British Journal of Educational Psychology, 90(2): 282-300. https://doi.org/10.1111/bjep.12281

[5] Ayache, F., Alti, A. (2020). Performance evaluation of machine learning for recognizing human facial emotions. Revue d'Intelligence Artificielle, 34(3): 267-275. https://doi.org/10.18280/ria.340304 
[6] Kwon, S.K., Lee M., Shin D. (2015). Educational assessment in the republic of Korea: lights and shadows of high-stake exam-based education system. Assessment in Education: Principles, 24(1), 60-77. https://doi.org/10.1080/0969594x.2015.1074540

[7] Singh, G., Agrawal, S., Sohi, B.S. (2020). Handwritten Gurmukhi digit recognition system for small datasets. Traitement du Signal, 37(4): 661-669. https://doi.org/10. $18280 /$ ts. 370416

[8] Vuurberg, G., Vos, J., Christoph, L.H., Vos, R.D. (2019). The effectiveness of interprofessional classroom-based education in medical curricula: a systematic review. Journal of Interprofessional Education and Practice, 15: 157-167. https://doi.org/10.1016/j.xjep. 2019.01.007

[9] Wolf, M.K., Faulkner-Bond, M. (2016). Validating English language proficiency assessment uses for English learners: academic language proficiency and content assessment performance. Educational Measurement Issues \& Practice, 35(2): 6-18. https://doi.org/10. $\underline{1111 / \text { emip. } 12105}$

[10] Wu, Y.T., Wang, A.Y. (2015). Technological, pedagogical, and content knowledge in teaching English as a foreign language: representation of primary teachers of English in Taiwan. The Asia-Pacific Education Researcher, 24(3): 525-533. https://doi.org/10.1007/s40299-015-0240-7

[11] Kirkpatrick, R., Gyem, K. (2012). Washback effects of the new English assessment system on secondary schools in Bhutan. Language Testing in Asia, 2(4), 5-32. https://doi.org/10.1186/2229-0443-2-4-5

[12] Darling-Hammond, L., Newton, S.P., Wei, R.C. (2013). Developing and assessing beginning teacher effectiveness: the potential of performance assessments. Educational Assessment Evaluation \& Accountability, 25(3): 179-204. https://doi.org/10.1007/s11092-0139163-0

[13] Hong, J.S., Han, D.H., Kim, Y.I., Bae, S.J., Kim, S.M., Renshaw, P. (2017). English language education on-line game and brain connectivity. Recall, 29(1): 3-21. https://doi.org/10.1017/s0958344016000173

[14] Aman, S., Rinkle R. (2020). Ensembled machine learning framework for drug sensitivity prediction. IET Systems Biology, 14(1): 39-46. https://doi.org/10.1049/iet-syb.2018.5094

[15] Zhang, Y., Michi, A., Wagner, J., Andre, E., Schuller, B., Weninger, F. (2019). A generic human-machine annotation framework based on dynamic cooperative learning. IEEE Transactions on Cybernetics, 50(3): 1230-1239. https://doi.org/10.1109/tcyb.2019.290 $\underline{1499}$

[16] Wen, J., Wei, X.C., He, T., Zhang, S.S. (2020). Regression analysis on the influencing factors of the acceptance of online education platform among college students. Ingénierie des Systèmes d'Information, 25(5): 595-600. https://doi.org/10. 18280/isi.250506

[17] Zhang, H. (2020). Research on spoken English analysis model based on transfer learning and machine learning algorithms. Journal of Intelligent and Fuzzy Systems, 38(6): 73777387. https://doi.org/10.3233/jifs-179811

[18] Grajzl, P., Murrell, P. (2020). A machine-learning history of English caselaw and legal ideas prior to the industrial revolution ii: applications. Journal of Institutional Economics, 17(2): 201-216. https://doi.org/10.1017/s1744137420000363

[19] Wu, J., Chen, B. (2020). English vocabulary online teaching based on machine learning recognition and target visual detection. Journal of Intelligent and Fuzzy Systems, 39(2): 1745-1756. https://doi.org/10.3233/jifs-179948

[20] Li, P., Jiang, S. (2020). Analysis of the characteristics of English part of speech based on unsupervised machine learning and image recognition model. Journal of Intelligent and Fuzzy Systems, 39(2): 1891-1901. https://doi.org/10.3233/jifs-179960

[21] Baboota, R., Kaur, H. (2018). Predictive analysis and modelling football results using machine learning approach for English premier league. International Journal of Forecasting, 35(2): 741-755. https://doi.org/10.1016/j.ijforecast.2018.01.003 
[22] Abdellaoui, M., Douik, A. (2020). Human action recognition in video sequences using deep belief networks. Traitement du Signal, 37(1): 37-44. https://doi.org/10.18280 /ts.370105

[23] Luong, N.Q., Besacier, L., Lecouteux, B. (2015). Towards accurate predictors of word quality for machine translation: lessons learned on French - English and English - Spanish systems. Data \& Knowledge Engineering, 96: 32-42. https://doi.org/10.1016/j. datak.2015.04.003

[24] Özbay, E., Çınar, A. (2019). A comparative study of object classification methods using 3D Zernike moment on 3D point clouds. Traitement du Signal, 36(6): 549-555. https://doi.org/10.18280/ts.360610

[25] Chandrasekaran, S. (2020). Feasibility study on machine-learning-based hybrid renewable energy applications for engineering education. Computer Applications in Engineering Education, 29(20): 465-473. https://doi.org/10.1002/cae.22237

[26] Silva, P.B., Andrade, M., Ferreira, S. (2020). Machine learning applied to road safety modeling: a systematic literature review. Journal of Traffic and Transportation Engineering (English Edition), 7(6): 775-790. https://doi.org/10.1016/j.jtte.2020.07. 004

[27] Hassan, Yasser F. (2018). Rough set machine translation using deep structure and transfer learning. Journal of Intelligent \& Fuzzy Systems, 34(6): 4149-4159. https://doi.org/10. $\underline{3233 / \text { jifs- } 171742}$

[28] Kholy, A.E., Habash, N. (2012). Orthographic and morphological processing for English Arabic statistical machine translation. Machine Translation, 26(1-2): 25-45. https://doi.org/10.1007/s10590-011-9110-0

[29] Balahur, A., Turchi, M. (2014). Comparative experiments using supervised learning and machine translation for multilingual sentiment analysis. Computer Speech \& Language, 28(1): 56-75. https://doi.org/10.1016/j.csl.2013.03.004

[30] Shah, D., Patel, D., Adesara, J., Hingu, P., Shah, M. (2021). Exploiting the Capabilities of Blockchain and Machine Learning in Education. Augmented Human Research, 6(1): 1-14. https://doi.org/10.1007/s41133-020-00039-7

[31] Iatrellis, O., Savvas, I.K., Kameas, A., Fitsilis, P. (2020). Integrated learning pathways in higher education: a framework enhanced with machine learning and semantics. Education and Information Technologies, 25(4): 3109-3129. https://doi.org/10.1007/s10639-020$\underline{10105-7}$

[32] Francisca, R., Ruz, G.A., Aldo, M., Budiman, M. (2018). Managing the 1920s' Chilean educational crisis: A historical view combined with machine learning. Plos One, 13(5): e0197429. https://doi.org/10.1371/journal.pone.0197429

\section{Author}

Lei Zhang Received the B.A. Degree in English teaching from Beihua University, Jilin, China, in 2002. the M.A. degree in comparative literature and world literature from Jilin University, Changchun, China, in 2008. M.A. degree in applied linguistics and ELT from St. Mary's University, London, the U.K., 2018. She has been on the faculty of Jilin Institute of Chemical Technology. Her research interests include English language teaching and British literature. Email: goldenchina 79@163.com

Article submitted 2021-03-15. Resubmitted 2021-04-22. Final acceptance 2021-04-23. Final version published as submitted by the authors. 